\title{
Einladung
}

\section{zur fünfzigsten Versammlung}

\section{Deutscher Naturforscher und Aerzte.}

Die neunundvierzigste Versammlung deutscher Naturforscher und Aerzte hat im September vorigen Jabres in Hamburg zu dem diesjährigen Versammlungsort München gewählt und die Unterzeichneten mit der Geschäftsführung beauftiagt.

Auf das Gesuch der Letzteren hat sich ein aus Vertretern und Freunden der Natumwissenschaften und Medicin, aus Delegirten der wissenschaftlichen Vereine, aus den beiden Buirgermeistern, Mitgliedern der städtischen Behörden und aus angesehenen Btirgern bestehendes Comité gebildet, auf dessen Beschlïssen das umstehend mitgetbeilte Programm beruht.

Einem seit Jahren vielfach geäusserten Wunsche entsprechend ist in dem Programm der wissenschaftliche Charakter der Versammlung vorwaltend berïcksichtigt. Die Vergnügungen sind auf das bescheidenste Mass beschränkt, von Bewirthungen, glänzenden Festen sowie von einem allgemeinen Festessen wurde abgesehen. Dafïr wird von Seiten der einführenden Sections-Vorstände für den ungehemmten und anregenden Verkehr der Fachgenossen innerhalb der Sectionen durch sorgfältige Vorbereitung der Sitzungen, sowie durch Beschaffung von Localen zu regelmässigen abendlichen Zusammenkünften Sorge getragen werden.

Auf jede Subrention ron Seite der Regierung oder der Stadt wurde grundsätzlich Verzicht geleistet. Sämmtliche Ausgaben sollen aus den eigenen Einnahmen bestritten werden, so dass im Falle des Gelingens dieses Versuches die Versammlungen in Zukunft bei der Wahl der Zusammenkunftsorte äusseren Rücksichten in geringerem Maasse als bisher Rechnung zu tragen haben werden.

Indem wir noch die Mittheilung beiftigen, dass viele deutsche und österreichische Eisenbahn-Verwaltungen Fabrpreis-Ermässigungen zugesichert haben, laden wir die Herren Naturforscher und Aerzte zum Besuche dieser Versammlung ein und stellen zugleich an diejenigen geehrten Mitglieder und Theilnehmer, welche sich durch Vorträge oder Demonstrationen in den Sectionen zu betheiligen beabsichtigen, das Ansuchen, die bezüglichen Themata ibrer Mittheilungen den Herren Sectionsvorständen womöglich schon vor Beginn der Versammlung kund zu geben.

M ünchen, im Juli 1877.

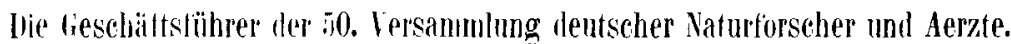

Dr. v. Pettenkofer.

Dr. Zittel. 